\title{
Bioactive Sphingolipids and Complement Cascade as New Emerging Regulators of Stem Cell Mobilization and Homing
}

\author{
Mariusz Z. Ratajczak ${ }^{1,2 *}$ and ChiHwa Kim ${ }^{1}$ \\ ${ }^{1}$ Stem Cell Biology Program at the James Graham Brown Cancer Center, University of Louisville, Louisville, Kentucky, USA \\ ${ }^{2}$ Department of Physiology, Pomeranian Medical University, Poland
}

\begin{abstract}
The a-chemokine stromal derived factor-1 (SDF-1) - seven transmembrane span receptor CXCR4 axis plays a crucial role in retention of hematopoietic stem progenitor cells (HSPCs) in BM. However, the mechanisms that govern mobilization/release of HSPCs from bone marrow (BM) into peripheral blood (PB) and direct a reverse process of their homing back into BM microenvironment after transplantation are still poorly understood. Augmenting evidence demonstrates that during both mobilization and myeloablative conditioning for transplantation a proteolytic microenvironment is induced in BM and complement cascade (CC) becomes activated. In this review we will present augmenting evidence that as result of induction of proteolytis microenvironment as well as $\mathrm{CC}$ activation bioactive sphingolipids - sphingosine - 1 phosphate (S1P) and ceramide-1-phosphate (C1P) together with CC cleavage fragments ( $\mathrm{C} 3 \mathrm{a}, \mathrm{C} 5 \mathrm{a}$ and $\mathrm{C} 5 \mathrm{~b}-\mathrm{C} 9)$ orchestrate both homing and mobilization of HSCPs.
\end{abstract}

\section{Introduction}

It is well known that the a-chemokine stromal derived factor-1 (SDF-1) - CXCR4 receptor axis plays crucial role in retention of hematopoietic stem and progenitor cells (HSPCs) in bone marrow [1]. However, chemotactic factors that direct release/mobilization of HSPCs from bone marrow (BM) into peripheral blood (PB) and their homing back after transplantation to the $\mathrm{BM}$ are not characterized very well. It is well known that HSPCs even under steady state conditions are continuously released from hematopoietic niches and circulate at detectable levels in PB. On other hand the phenomenon of enforced release of HSPCs from BM into PB is called mobilization and may be envisioned as a danger-sensing response mechanism triggered by hypoxia or mechanical- or infection-induced tissue damage and is a part of stress response [2-6]. Mobilization could be also induced by some pharmacological agents such as granulocyte colony stimulatingfactor (G-CSF) or small molecular antagonists of CXCR4 receptor (e.g., AMD3100). Augmenting evidence demonstrates that in BM during both mobilization and myeloablative conditioning for transplantation is induced proteolytic microenvironment and complement cascade (CC) becomes activated $[7,8]$. As we will discuss in this chapter both of these processes have important regulatory functions in trafficking of HSPCs.

To explain mobilization and homing a concept of "tug of war" has been proposed for chemotactic stromal derived factor-1 (SDF-1) gradient between $\mathrm{BM}$ and $\mathrm{PB}$ that decides if cells will be released/mobilized from $\mathrm{BM}$ into $\mathrm{PB}$ or home back from $\mathrm{PB}$ to $\mathrm{BM}$ microenvironment (Figure 1 panel A). However, in light of new observations changes in the SDF-1 gradient between BM and PB do not always support SDF-1 having a crucial role as chemoattractant present in PB that directs egress/mobilization of HSPCs. For example as recently reported by others and us the plasma SDF-1 level does not always correlate with mobilization of HSPCs [12-15]. On other hand some doubts also accumulated about an exclusive role for SDF-1 in homing of HSPCs into BM. This is based on observations that i) $\mathrm{CXCR}^{-/}$- fetal liver HSPCs may home to BM in an SDF-1-independent manner [16], ii) homing of murine HSPCs made refractory to SDF1 by incubation and co-injection with a CXCR4 receptor antagonist (e.g., AMD3100) is normal or only mildly reduced [17], and finally iii) HSPCs in which CXCR4 has been knocked down by means of an SDF1 intrakine strategy may also engraft in lethally irradiated recipients
[18]. All this strongly suggests the existence of other factors beside SDF-1 that are involved in the mobilization and homing of HSPCs.

To support this further, SDF-1 that is a well known potent chemoattractant for HSPCs as a peptide is highly susceptible to degradation by proteases that are elevated both in PB during stem cell mobilization and in the BM microenvironment after myeloablative conditioning for transplantation. To support this we did not observe by employing sensitive ELISA measurement i) significant increases in SDF-1 plasma level during mobilization [19], ii) differences in plasma level between poor and good moilizers and iii) and unexpectedly noticed a significant decrease of SDF-1 level in murine BM after myeloablative conditioning for transplantation $[9,10]$.

In this review we will present mounting evidence that elements of innate immunity such as complement cascade (CC) cleavage fragments (e.g., C3a and C5a), generation of C5b-C9 - membrane attack complex (MAC) together with release of some bioactive lipids such as sphingosine - 1 phosphate (S1P) and ceramide-1-phosphate (C1P) from the damaged/leaky cells all together regulate trafficking of HSPCs (Figure 1 panel B).

\section{Induction of proteolytic microenrironment in $\mathrm{BM}$ affects SDF-1-CXCR4 and VLA4-VCAM-1 interactions}

HSPCs are retained in the BM niches due to SDF-1-CXCR4 receptor and Very Late Antigen-4 (VLA-4; $\alpha_{4} \beta_{1}$ integrin) and its ligand Vascular Adhesion Molecule-1 (VCAM-1; CD106) interactions. While HSPCs express CXCR4 and VLA-4, their corresponding ligands SDF-1 and VCAM-1 are expressed by cells in BM microenvironment

*Corresponding author: Mariusz Z. Ratajczak MD, PhD, Stem Cell Institute at James Graham Brown Cancer Center, University of Louisville, 500 S. Floyd Street Rm. 107, Louisville, KY 40202, USA, Tel: (502) 852-1788 ; Fax: (502) 852-3032; E-mail: mzrata01@louisville.edu

Received March 01, 2011; Accepted March 02, 2011; Published March 30, 2011

Citation: Ratajczak MZ, Kim CH (2011) Bioactive Sphingolipids and Complement Cascade as New Emerging Regulators of Stem Cell Mobilization and Homing. J Stem Cell Res Ther 2:e102. doi:10.4172/2157-7633.1000e102

Copyright: (c) 2011 Ratajczak MZ, et al. This is an open-access article distributed under the terms of the Creative Commons Attribution License, which permits unrestricted use, distribution, and reproduction in any medium, provided the original author and source are credited. 
(e.g., osteoblasts and fibroblasts) [20,21]. On other hand augmenting evidence indicates that both mobilization after administration of G-CSF as well as conditioning for hematopoietic transplantation by radio-chemotherapy induces highly proteolytic microenvironment in $\mathrm{BM}$ microenvironment. Several proteolytic enzymes are released in BM such as metalloproteinases (MMPs), cathepsin G (CG) and neutrophil elastaze (NE). All these enzymes affect integrity of SDF-1 and CXCR4 as well as VCAM-1 and VLA-4 proteins. During mobilization of HSPCs proteolytic enzymes attenuate retention signals of SDF-1-CXCR4 and VCAM-1-VLA-4 axes and facilitate release of HSPCs into PB. On the other hand after conditioning for hematopoietic transplantation by radio-chemotherapy proteolytic enzymes decrease SDF-1 level in BM what impairs homing of HSPCs.

Based on this we become interested in other potential factors that in addition to SDF-1 could chemoattract HSPCs and thus play a role in their mobilization and homing. Interestingly we noticed that both PB plasma as well as media conditioned by BM cells isolated from lethally irradiated mice show chemotactic activity against HSPCs and this activity is susceptible to charcoal extraction what suggested involvement of bioactive sphingolipids. To support this notion, it is known that sphingolipids, which are important components of cell membranes, give rise to two bioactive derivatives, sphingosine-1 phosphate (S1P) and ceramide-1 phosphate (C1P), with S1P already identified as a chemoattractant for HSPCs [13] and C1P for monocytes [22]. Our data indicate that both these bioactive lipids play an important and underappreciated role in trafficking of HSPCs, and orchestrate both egress as well as homing of HSPCs and this will discussed below in this review $[9,10]$.

\section{Cleavage fragments of complement cascade (CC) as important modulators of stem cell trafficking}

We noticed that both mobilization of HSPCs as well as myeloablative conditioning for transplantation activate complement cascade (CC) in murine BM and lead to the release of $\mathrm{C} 3$ and $\mathrm{C} 5$ cleavage fragments (liquid phase soluble - C3a, ${ }_{\text {desArg }} \mathrm{C} 3 \mathrm{a}, \mathrm{C} 5 \mathrm{a},{ }_{\text {desArg }} \mathrm{C} 5 \mathrm{a}$ and solid phase $\mathrm{iC} 3 \mathrm{~b}$ ) as well as deposition of soluble and solid phase C5b-C9 (membrane attack complex - MAC) in BM microenvironment. The activation of CC during HSPC mobilization and conditioning for hematopoietic transplantation was confirmed by i) ELISA to detect $\mathrm{C} 3 \mathrm{a}$ and C5a clevage fragments in plasma [23], ii) immunofluorescence showing deposition of $\mathrm{iC} 3 \mathrm{~b}$ on $\mathrm{BM}$ stroma and endothelial cells [24-26] and iii) histochemical detection of deposition of solid phase membrane attack complex (MAC) fragments in BM tissue [14].

Activation of CC is an important and evolutionarily conserved regulatory mechanism for sensing and responding to inflammation and organ injury and thus it should not be surprising that mobilization and homing of stem cells is directed by this evolutionary old mechanism. Since the CC is activated as a result of i) inflammation, ii) release of CC activating factors from damaged tissues, or iii) strenuous exercise as a result of hypoxia, the release of stem cells into circulation could be envisioned as part of CC-mediated immune surveillance and response to inflammation and organ/tissue damage. Work from our laboratory demonstrates that $\mathrm{CC}$ activation in $\mathrm{BM}$ is triggered by several mobilizing agents, including granulocyte colony stimulating factor (G-CSF), mobilizing polysaccharides like zymosan, as well as CXCR4 receptor antagonist - AMD3100 $[8,23,26]$. On other hand it is also triggered by conditioning to transplantation by radio-chemotherapy.

Data from our laboratory indicate that CC cleavage fragments affect the retention/mobilization process of HSPCs differently [8, $23,24,26,27$. That is, while C3 cleavage fragments (C3a or ${ }_{\text {desArg }} \mathrm{C} 3 \mathrm{a}$ and $\mathrm{iC} 3 \mathrm{~b}$ ) increase retention of HSPCs in BM, C5 (C5a or ${ }_{\text {desArg }} \mathrm{C} 5 \mathrm{a}$ ) cleavage fragments direct egress of granulocytes and monocytes into $\mathrm{PB}$ (Figure 2). The role of C3a and ${ }_{\text {desrarg }} \mathrm{C} 3 \mathrm{a}$ in retention of HSPCs in $\mathrm{BM}$ has been explained by ability of these cleavage fragments to increase responsiveness of HSPCs to SDF-1 retention signals in $\mathrm{BM}$, and $\mathrm{iC} 3 \mathrm{~b}$ has been shown to play an important role in tethering HSPCs in BM in complement receptor-3 (CR3) dependent manner [24]. In contrast C5a and ${ }_{\text {desArg }}$ C5A play crucial role in executing mobilization by activating/ degranulating granulocytes and chemoattracting granulocytes and monocytes into PB. To support this granulocytes and monocytes play a crucial role in mobilization process and are a first wave of cells that leave BM during mobilization [8]. These cells are enriched for proteolytic enzymes necessary to permeabilize BM-blood barrier and thus pave a way for egress of HSPCs which follow in their footsteps [8].

The crucial role of CC in stem cell mobilization process was evidenced in mobilization studies performed in C3- and C5-deficient animals, which revealed that $\mathrm{C} 3$-deficient mice are easy mobilizers $[24,26,27]$ and C5-deficient mice mobilize poorly [23]. This also demonstrates that retention/mobilization of HSPCs is tightly regulated at different levels of CC activation. However, the major role of CC, is to execute process of mobilization. This as demonstrated involves final product of CC activation - soluble MAC that releases in BM sinusoids S1P from erythrocytes. As we already reported plasma level of S1P and not SDF-1 creates than a major chemotactic gradient for HSPCs to egress into $\mathrm{PB}[14]$.

On the other hand, as we have recently demonstrated C5 deficient mice that have defect in activation of distal steps of CC activation and do not generate C5b-C9 (MAC) are not only poor mobilizers but also show defect in hematopoietic reconstitution after transplantation. This indicates that $\mathrm{CC}$ activation with release of $\mathrm{C} 3 \mathrm{a},{ }_{\operatorname{desArg}} \mathrm{C} 3 \mathrm{a}$ and $\mathrm{iC} 3 \mathrm{~b}$ and generation of soluble MAC play an important role not only in executing optimal mobilization but also in lodging/homing of HSPCs into BM microenvironment. Our experiments in $\mathrm{C}^{-/}$and $\mathrm{C}^{-/}$and normal wt mice revealed for a first time an important and underappreciated role of CC activation in this process. As mentioned above while C3a and ${ }_{\text {desArg }} \mathrm{C} 3 \mathrm{a}$ enhance/prime responsiveness of HSPCs to homing gradient of SDF-1, iC3b plays an important role in tethering of HSPCs in BM microenvironment [26]. On other hand soluble MAC that has been reported to affect biology of several cell types $[28,29]$ directly affects HSPCs homing.

This novel role of soluble MAC is supported by defect in homing/ engraftment of HSPCs in BM of $\mathrm{C} 5$ deficient mice and demonstrates unrecognized until now role of soluble MAC in supporting several steps that facilitate lodging of HSPCs into BM microenvironment. First, soluble MAC enhances secretion of SDF-1 by BM stroma cells, what probably contributes in ameliorating drop in BM SDF-1 level in proteolytic microenvironment induced by conditioning for transplantation. Second, soluble MAC increases adhesiveness of HSPCs to BM-derived fibroblasts. These effects are supported as demonstrated by ability of soluble MAC to induce signaling (phosphorylation of MAPKp42/44 and AKT) in normal HSPCs.

Soluble MAC however, if employed alone does not chemottract HSPC and as does not affect either expression of CXCR4 and VLA-4 on HSPCs or proliferation of clonogeneic progenitors. Of note receptor/s for soluble MAC are not identified yet. 
Citation: Ratajczak MZ, Kim CH (2011) Bioactive Sphingolipids and Complement Cascade as New Emerging Regulators of Stem Cell Mobilization and Homing. J Stem Cell Res Ther 2:e102. doi:10.4172/2157-7633.1000e102

\section{Interplay between bioactive lipids and CC in trafficking of HSPCs}

Interestingly, as reported activation of $\mathrm{CC}$ correlates with increase of BM-level of S1P and C1P [11]. We found that while the S1P level increases in $\mathrm{PB}$ mainly during mobilization, the $\mathrm{C} 1 \mathrm{P}$ concentration in $\mathrm{BM}$ microenvironment increases after myeloablative conditioning for transplantation. As mentioned both these sphongolipids are potent chemoattractants for HSPCs.

Based on these findings, we proposed a new paradigm in which the S1P:C1P ratio plays an important role in trafficking of HSPCs. Accordingly, while S1P is a major chemoattractant that directs egress of HSPCs from BM into PB, C1P is released from damaged cells in BM microenvironment after myeloablative conditioning and together with SDF-1 creates a homing gradient for circulating HSPCs.
We also postulate that the S1P:C1P ratio may also play a more universal role in trafficking of stem cells and is involved in regulating migration of circulating mesenchymal stem cells (MSCs), endothelial progenitor cells (EPCs), and very small embryonic-like (VSEL) stem cells [30-33]. Accordingly, while S1P plays a role in egress of these cells into PB, C1P released from damaged cells (e.g., in infarcted myocardium or brain tissue after stroke) may chemoattract circulating stem cells for potential organ repair.

\section{"Priming phenomenon" enhances responsiveness of CXCR4 receptor to SDF-1 gradient}

As discussed above our recent data indicate that SDF-1 level does not significantly change in PB during mobilization and even decreases due to proteolytic microenvironment in $\mathrm{BM}$ after conditioning for
A

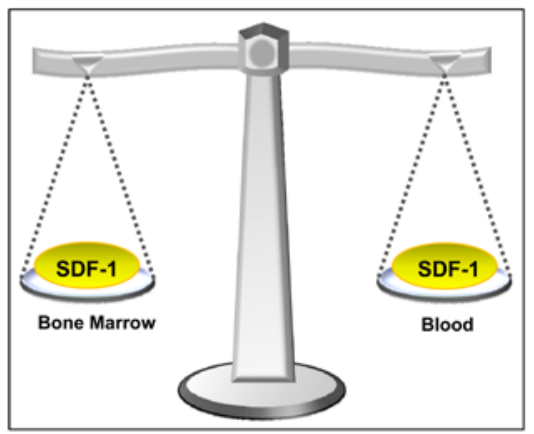

B

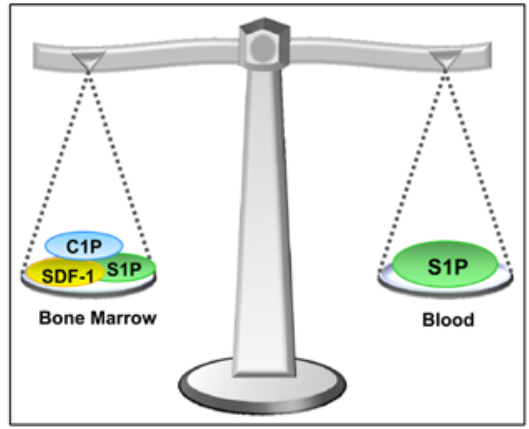

Figure 1: Concept of chemotactic "tug of war" gradient between BM and PB to explain mobilization and homing of HSPCs. Panel A - It has been postulated that SDF-1 gradient between BM and PB regulates trafficking of HSPCs (homing vs. mobilization). In steady state conditions this gradient should be in balance. As proposed during mobilization increase in plasma SDF-1 level directs egress of HSPCs and vice versa increase in BM SDF-1 level after conditioning for transplantation was supposed to direct engraftment of HSPCs. Panel B - Novel model in which bioactive lipids S1P and C1P modulate function of SDF-1 in mobilization and homing.

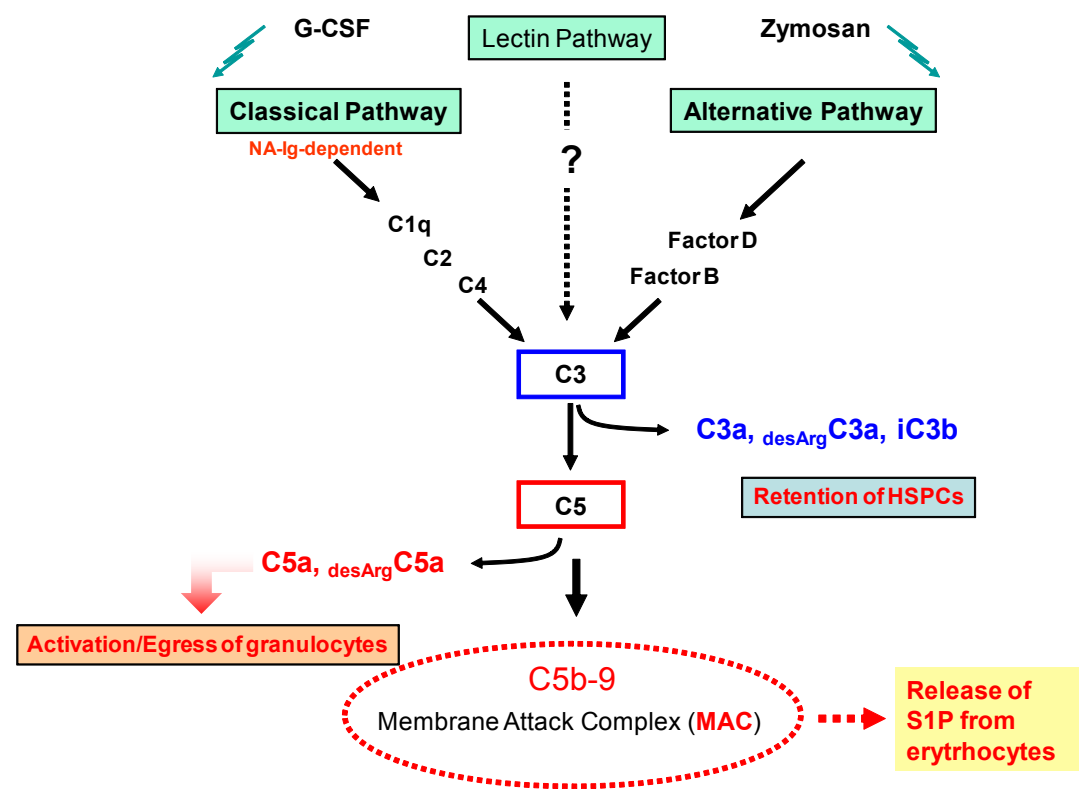

Figure 2: Complement cascade activation products differentially modulate stem cell trafficking. Upon activation of the CC system C3 and C5 cleavage products play opposite roles in the retention or mobilization of cells, respectively. While liquid phase C3 cleavage fragments $\left(\mathrm{C} 3 \mathrm{a}\right.$ and $\mathrm{C} 3 \mathrm{a}_{\text {desarg }}$ ) enhance responsiveness of HSPC to an SDF-1 gradient, solid phase cleavage fragment iC3b deposited onto surrounding surfaces helps to retain HSPC in their niche, C5 cleavage fragments (C5a and $\quad \mathrm{C} 5 \mathrm{a}$ ) promote mobilization of HSPC by degranulation of granulocytes (release of proteolytic enzymes) and chemoattracting them into PB. Granulocytes are first cells that egress from BM and thus pave a way for HSPCs that follow their footsteps. Thus we propose that an activated CC can affect stem cell mobilization in a negative (C3) or a positive (C5) way. 


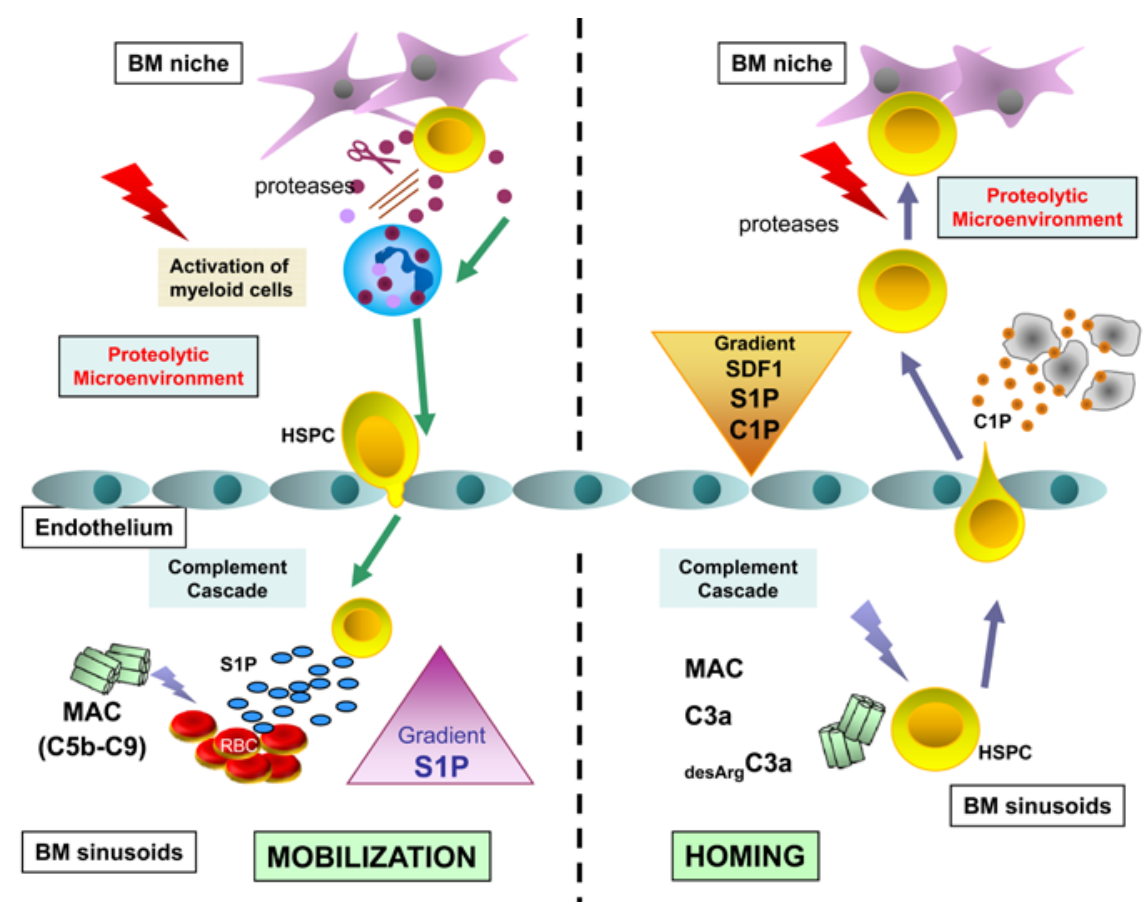

Figure 3: Proposed scheme depicting a novel proposed role of complement cascade activation and bioactive lipids in mobilization and homing of HSPCs. Panel A - G-CSF-directed mobilization induces in BM both proteolytic microenvironment and activates complement cascade (CC). Proteolytic enzymes attenuate interaction of HSPCs with homing signals (e.g., SDF-1-CXCR4 and VCAM-1-VLA-4 axes) and in addition activated CC via MAC releases form erythrocytes that are present in BM sinusoids sphingosine-1 phosphate (S1P). Released from erythrocytes S1P is a major chemoattractant that directs egress of HSPCs into PB. Panel B - Myeloablative conditioning for transplantation also induces in BM both i) proteolytic microenvironment and ii) activates CC. Proteolytic microenvironment degradates SDF-1, but at the same time several bioactive lipids including C1P are released from damaged BM cells that chemoatrract HSPCs. Furthermore, some elements of activated CC such as for example C3a increase responsiveness of HSPCs to SDF-1, C1P and S1P homing signals.

transplantation by lethal irradiation [7,19,34]. Thus, as demonstrated at Figure 1 the concept of "tug of war" SDF-1 gradient between BM and $\mathrm{PB}$ does not explain very well homing and mobilization of HSPCs. Moreover, since for biological activity of SDF-1 are crucial few aminoacids located at N-terminus of this peptide, we noticed that detection of SDF-1 protein in tissues not always correlate with its chemotactic activity and usually is even much lower than expected based on ELISA or histochemical data.

On other hand as we reported responsiveness of HSPCs to SDF-1 could be enhanced by several molecules [8]. In addition to $\mathrm{C} 3$ cleavage fragments (C3a and ${ }_{\text {desArg }} \mathrm{C} 3 \mathrm{a}$ ) also i) cathelicidin and $\beta 2$-defensin cationic peptides released from activated by C5a granulocytes [8], ii) thrombin $[35,36]$, iii) hyaluronic acid [36, 37], iv) membrane derived-microvesicles [38], and v) as we recently found MAC increase responsiveness of HSPCs to SDF-1 gradient [11]. The basis for this phenomenon is incorporation of CXCR4 into membrane lipid rafts that makes CXCR4 receptor more responsive to SDF-1 gradient. As result of this priming effect the lower doses of SDF-1 become "more biologically significant" for stem cell trafficking.

Further studies are needed to see if in addition to CXCR4 also S1P receptors are lipid raft regulated. More work is also required to identify receptor for C1P. However this receptor/s has been not indentified yet, our signal transduction data indicate that this receptor is expressed on HSPCs and is sensitive to pertussis toxin, what supports that it could probably be Gai-protein coupled type receptor.

\section{Conclusions}

Our recent data provide more evidence that innate immunity and the CC regulate trafficking of HSPCs by modulating the migratory properties of HSPCs by C3a and SMAC that i) enhance S1P and C1P level in BM, ii) increase responsiveness of HSPCs to SDF-1, S1P and $\mathrm{C} 1 \mathrm{P}$ and iii) stimulate adhesion of HSPCs to BM stroma. Based on this we propose modulation of CC as a novel strategy for controlling both mobilization and homing of HSPCs. This could be achieved for example by exposure of HSPCs before transplantation to some cationic peptides (e.g., C3a or cathelicidin) that enhance responsiveness of these cells to homing factors.

We also propose a new paradigm in which the ratio between bioactive lipids (S1P : C1P) plays an important role in mobilization and homing of HSPCs. Accordingly, S1P and C1P that do not contain peptide bonds are in contrast to SDF-1 are resistant to proteolytic enzymes, and while S1P is a major chemoattractant that directs egress of HSPCs from BM into PB, C1P is released from damaged cells in BM after myeloablative conditioning and promotes with SDF-1 homing of circulating HSPCs. We also postulate that the S1P:C1P ratio plays a more universal role and is involved in regulating migration of other types of stem cells, such as circulating mesenchymal stem cells (MSCs), endothelial progenitor cells (EPCs), and very small embryonic-like (VSEL) stem cells. Similar mechanisms of homing play probably role in recruitment of stem cells in other types of organ injury e.g., heart infarct or stroke.

\section{Acknowledgments}

This work was supported by NIH R01 DK074720, Stella and Henry Endowment and EU structural funds, Innovative Economy Operational Program POIG.01.01.0100-109/09-01 and the Henry M. and Stella M. Hoenig Endowment to MZR.

\section{References}

1. Lapidot T, Dar A, Kollet O (2005) How do stem cells find their way home? Blood 106: $1901-10$. 
Citation: Ratajczak MZ, Kim CH (2011) Bioactive Sphingolipids and Complement Cascade as New Emerging Regulators of Stem Cell Mobilization and Homing. J Stem Cell Res Ther 2:e102. doi:10.4172/2157-7633.1000e102

2. Méndez-Ferrer S, Chow A, Merad M, Frenette PS (2009) Circadian rhythms influence hematopoietic stem cells. Curr Opin Hematol 16: 235-242.

3. Slavin S, Mumcuoglu M, Landsberg-Weisz A, Kedar E (1989) The use of recombinant cytokines for enhancing immunohematopoietic reconstitution following bone marrow transplantation. I. Effects of in vitro culturing with IL3 and GM-CSF on human and mouse bone marrow cells purged with mafosfamide. Bone Marrow Transplant 4: 459-464.

4. Wojakowski W, Tendera M, Kucia M, Zuba-Surma E, Paczkowska E, et al. (2009) Mobilization of bone marrow-derived Oct-4+ SSEA-4+ very smal embryonic-like stem cells in patients with acute myocardial infarction. J Am Coll Cardiol 53: 1-9.

5. Paczkowska E, Kucia M, Koziarska D, Halasa M, Safranow K, et al. (2009) Clinical evidence that very small embryonic-like stem cells are mobilized into peripheral blood in patients after stroke. Stroke 40: 1237-1244.

6. Kucia M, Zhang YP, Reca R, Wysoczynski M, Machalinski B, et al. (2006) Cells enriched in markers of neural tissue-committed stem cells reside in the bone marrow and are mobilized into the peripheral blood following stroke. Leukemia 20: $18-28$.

7. Levesque JP, Hendy J, Takamatsu Y, Williams B, Winkle IG, et al. (2002) Mobilization by either cyclophosphamide or granulocyte colony-stimulating factor transforms the bone marrow into a highly proteolytic environment. Exp Hematol 30: 440-449.

8. Lee HM, Wu W, Wysoczynski M, Liu R, Zuba-Surma EK, et al. (2009) Impaired mobilization of hematopoietic stem/progenitor cells in C5-deficient mice supports the pivotal involvement of innate immunity in this process and reveals novel promobilization effects of granulocytes. Leukemia 23: 2052-2062.

9. Kim CH, Wan W, Abdel-Latif M, Wysoczynski M, Kucia M, et al. (2010) Evidence that a bioactive lipid, ceramide 1-phosphate (C1P), is upregulated in bone marrow microenvironment after myeloablative therapy and is a potentia novel homing factor for hematopoietic stem cells. ASH meeting, Abstract \#401.

10. Kim CH, Wan W, Rui L, Kucia M, Laughlin MJ, et al. (2010) A novel paradigm in stem cell trafficking: the ratio of peripheral blood sphingosine-1 phosphate $(\mathrm{S} 1 \mathrm{P})$ to bone marrow ceramide-1 phosphate $(\mathrm{C} 1 \mathrm{P})$ regulates mobilization and homing of hematopoietic stem cells. ASH meeting, Abstract \#554.

11. Kim CH, Wan W, Rui L, Kucia M, Ratajczak J, et al. (2010) An unexpected role for the complement C5b-C9 membrane attack complex (MAC) in trafficking of hematopoietic stem/progenitor cells - a novel unexpected link between innate immunity and hematopoiesis. ASH meeting, Abstract \#555.

12. Hanel P, Andre'ani $P$, Graler MH (2007) Erythrocytes store and release sphingosine 1-phosphate in blood. FASEB J 21: 1202-1209.

13. Seitz G, Boehmler AM, Kanz L, Möhle R (2005) The role of sphingosine 1-phosphate receptors in the trafficking of hematopoietic progenitor cells. Ann NY Acad Sci 1044: 84-89.

14. Ratajczak MZ, Lee HM, Wysoczynski M, Wan W, Marlicz W, et al. (2010) Novel insight into stem cell mobilization-plasma sphingosine-1-phosphate is a major chemoattractant that directs the egress of hematopoietic stem progenitor cells from the bone marrow and its level in peripheral blood increases during mobilization due to activation of complement cascade/membrane attack complex. Leukemia 24: 976-85.

15. Marquez-Curtis LA, Turner AR, Sridharan S, Ratajczak MZ, JanowskaWieczorek A (2010) The Ins and Outs of Hematopoietic stem cells: Studies to Improve Transplantation Outcomes. Stem Cell Rev [Epub ahead of print].

16. Ma Q, Jones D, Springer TA (1999) The Chemokine Receptor CXCR4 Is Required for the Retention of B Lineage and Granulocytic Precursors within the Bone Marrow Microenvironment. Immunity 10: 463-471.

17. Christopherson KW 2nd, Hangoc G, Mantel CR, Broxmeyer HE (2004) Modulation of Hematopoietic Stem Cell Homing and Engraftment by CD26. Science 305: 1000-1003

18. Onai N, Zhang YY, Yoneyama H, Kitamura T, Ishikawa S, et al. (2000) Impairment of lymphopoiesis and myelopoiesis in mice reconstituted with bone marrow-hematopoietic progenitor cells expressing SDF-1-intrakine. Blood 96: 2074-2080.

19. Levesque JP, Hendy J, Takamatsu Y, Simmons PJ, Bendal, LJ (2003) Disruption of the CXCR4/CXCL12 chemotactic interaction during hematopoietic stem cell mobilization induced by GCSF or cyclophosphamide. J Clin Invest 111: $187-196$.
20. Levesque JP, Takamatsu Y, Nilsson SK, Haylock DN, Simmons PJ (2001) Vascular cell adhesion molecule-1 (CD106) is cleaved by neutrophil proteases in the bone marrow following hematopoietic progenitor cell mobilization by granulocyte colony-stimulating factor. Blood 98: 1289-1297.

21. Peled A, Grabovsky V, Habler L, Sandbank J, Arenzana-Seisdedos F, et al. (1999) The chemokine SDF-1 stimulates integrin-mediated arrest of CD34+ cells on vascular endothelium under shear flow. J Clin Invest 104: 1199-1211.

22. Granado MH, Gangoiti P, Ouro A, Arana L, González M, et al. (2009) Ceramide 1-phosphate $(\mathrm{C} 1 \mathrm{P})$ promotes cell migration Involvement of a specific C1P receptor. Cell Signal 21: 405-412.

23. Lee HM, Wysoczynski M, Liu R, Shin DM, Kucia M, et al. (2010) Mobilization studies in complement-deficient mice reveal that optimal AMD3100 mobilization of hematopoietic stem cells depends on complement cascade activation by AMD3100-stimulated granulocytes. Leukemia 24: 573-582.

24. Ratajczak MZ, Reca R, Wysoczynski M, Kucia M, Baran JT, et al. (2004) Transplantation studies in C3-deficient animals reveal a novel role of the third complement component (C3) in engraftment of bone marrow cells. Leukemia 18: $1482-1490$.

25. Ratajczak MZ, Reca R, Wysoczynski M, Yan J, Ratajczak J (2006) Modulation of the SDF-1-CXCR4 axis by the third complement component (C3)-implications for trafficking of CXCR4+ stem cells. Exp Hematol 34: 986-995.

26. Reca R, Cramer D, Yan J, Laughlin MJ, Janowska-Wieczorek A, et al. (2007) A novel role of complement in mobilization: immunodeficient mice are poor granulocyte-colony stimulating factor mobilizers because they lack complement-activating immunoglobulins. Stem Cells 25: 3093-3100.

27. Wysoczynski M, Kucia M, Ratajczak J, Ratajczak MZ (2007) Cleavage fragments of the third complement component (C3) enhance stromal derived factor-1 (SDF-1)-mediated platelet production during reactive postbleeding thrombocytosis. Leukemia 21: 973-982.

28. Chen $Y$, Yang $C$, Jin N, Xie Z, Tang $Y$, et al. (2007) Terminal complement complex C5b-9-treated human monocyte-derived dendritic cells undergo maturation and induce Th1 polarization. Eur J Immunol 37: 167-176.

29. Corallini F, Bossi F, Gonelli A, Tripodo C, Castellino G, et al. (2009) The soluble terminal complement complex (SC5b-9) up-regulates osteoprotegerin expression and release by endothelial cells: implications in rheumatoid arthritis. Rheumatology (Oxford) 48: 293-298.

30. Luster AD, Alon R, von Andrian UH (2005) Immune cell migration in inflammation: Present and future therapeutic targets. Nat Immunol 6: 11821190.

31. Ceradini DJ, Kulkarni AR, Callaghan MJ, Tepper OM, Bastidas N, et al. (2004) Progenitor cell trafficking is regulated by hypoxic gradients through HIF-1 induction of SDF-1. Nat Med 10: 858-864.

32. Kucia M, Wysoczynski M, Wu W, Zuba-Surma EK, Ratajczak J, et al. (2008) Evidence that very small embryonic-like stem cells are mobilized into peripheral blood. Stem Cells 26: 2083-2092.

33. Massberg S, Schaerli P, Knezevic-Maramica I, Köllnberger M, Tubo N, et al. (2007) Immunosurveillance by hematopoietic progenitor cells trafficking through blood, lymph, and peripheral tissues. Cell 131: 994-1008.

34. Pelus LM, Bian H, King AG, Fukuda S (2004) Neutrophil-derived MMP-9 mediates synergistic mobilization of hematopoietic stem and progenitor cells by the combination of G-CSF and the chemokines GRObeta/CXCL2 and GRObetaT /CXCL2delta4. Blood 103: 110-119.

35. Huber-Lang M, Sarma JV, Zetoune FS, Rittirsch D, Neff TA, et al. (2006) Generation of $\mathrm{C} 5 \mathrm{a}$ in the absence of $\mathrm{C} 3$ : a new complement activation pathway. Nat Med 12: 682-687.

36. Shirvaikar N, Marquez-Curtis LA, Ratajczak MZ, Janowska-Wieczorek A (2011) Hyaluronic Acid and Thrombin Upregulate MT1-MMP Through PI3K and Rac-1Signaling and Prime the Homing-Related Responses of Cord Blood Hematopoietic Stem/Progenitor Cells. Stem Cells Dev 20: 19-30.

37. Avigdor A, Goichberg P, Shivtiel S, Dar A, Peled A, et al. (2004) CD44 and hyaluronic acid cooperate with SDF-1 in the trafficking of human CD34+ stem/ progenitor cells to bone marrow. Blood 103: 2981-2989.

38. Janowska-Wieczorek A, Majka M, Kijowski J, Baj-Krzyworzeka M, Reca R, et al. (2001) Platelet-derived microparticles bind to hematopoietic stem/progenitor cells and enhance their engraftment. Blood 98: 3143-3149. 